\title{
Gambaran penggunaan ponsel pintar sebagai faktor risiko nyeri kepala primer pada mahasiswa angkatan 2013 Fakultas Kedokteran Universitas Sam Ratulangi Manado
}

\author{
${ }^{1}$ Kezia Oroh \\ ${ }^{2}$ Junita M. Pertiwi \\ ${ }^{2}$ Theresia Runtuwene
}

\author{
${ }^{1}$ Kandidat Skripsi Fakultas Kedokteran Universitas Sam Ratulangi Manado \\ ${ }^{1}$ Bagian Neurologi Fakultas Kedokteran Universitas Sam Ratulangi Manado \\ Email: Key.priskila@yahoo.com
}

\begin{abstract}
The aim of this research is to get a description of smart phone usage as a factor of primary headache to the students of medical faculty year 2013 Sam Ratulangi Unifersity of Manado. This research is a kind of descriptive research by approach of latitude cut. Received data are from primary data using questioner. From 243 of the total respondent there are 72 male respondents and 171 female respondents, with the percentages of each primary headache as follows: tension-type headache $72.84 \%$, migraine without aura $17.28 \%$, migraine with aura $8.64 \%$ and cluster headache $1.23 \%$. The most usage feature of the smart phone user is social media $(40.16 \%)$. The length of smart phone usage is 5 to 7 hours a day $(47.33 \%) .64 .61 \%$ of the respondents that using a smart phone experienced an eye ache. $48.98 \%$ of the respondents are those who do physic activities less than two times during fifteen minutes or more in one week. $48.56 \%$ of the respondents are using the smart phones with 30 degree neck declivity. Respondents who are using smart phones experienced tension-type headache is $75.71 \%$, migraine without aura $16.43 \%$, migraine with aura $7.15 \%$ and cluster headache $0.71 \%$.
\end{abstract}

Keywords: primary headache, smart phones

\begin{abstract}
Abstrak: Penelitian ini bertujuan untuk mendapatkan gambaran penggunaan ponsel pintar sebagai faktor risiko nyeri kepala primer pada mahasiswa angkatan 2013 fakultas kedokteran Universitas Sam Ratulangi. Jenis penelitian ini deskriptif dengan pendekatan potong lintang. Data yang didapat melalui data primer menggunakan kuesioner. Dari total 243 responden, diperoleh 72 responden laki-laki dan 171 responden perempuan, dengan presentase untuk setiap jenis nyeri kepala primer adalah sebagai berikut: nyeri kepala tipe tegang $72.84 \%$, migren tanpa aura $17.28 \%$, migren dengan aura $8.64 \%$ dan nyeri kepala klaster $1.23 \%$. Fitur yang sering digunakan pada ponsel pintar adalah sosial media (40.16\%). Lama penggunaan ponsel pintar 5-7 jam dalam sehari (47.33\%). 64.61\% dari responden yang menggunakan ponsel pintar terdapat keluhan mata. $48.98 \%$ dari responden adalah mereka yang melakukan aktivitas fisik < 2x selama > 15 menit dalam seminggu. 48.56\% responden menggunakan ponsel pintar dengan kemiringan leher $30^{\circ}$. Responden yang menggunakan ponsel pintar dan mengeluhkan nyeri kepala tipe tegang $75.71 \%$, migren tanpa aura $16.43 \%$, migren dengan aura $7.15 \%$ dan klaster $0.71 \%$.
\end{abstract}

Kata kunci: nyeri kepala primer, ponsel pintar

Nyeri kepala merupakan keluhan yang umum dialami oleh masyarakat. Menurut WHO (2012), Sekitar 47\% populasi dewasa di dunia setidaknya pernah mengalami satu kali nyeri kepala dalam satu tahun. ${ }^{1}$ Berdasarkan hasil penelitian multisenter 
berbasis rumah sakit pada lima rumah sakit di Indonesia, didapatkan prevalensi penderita nyeri kepala sebagai berikut: migren tanpa aura $10 \%$, migren dengan aura $1.8 \%$, episodic tension type headache $31 \%$, chronic tension type headache $24 \%$, cluster headache $0.5 \%$, dan mixed headache 14\%. Dari hasil pengamatan tersebut, nyeri kepala menduduki proporsi tempat teratas, sekitar $42 \%$ dari keseluruhan pasien neurologi. ${ }^{2}$ Salah satu penyebab terjadinya nyeri kepala adalah akibat penggunaan media elektronik. Penelitian yang dilakukan oleh Nurwulandari $^{3}$ mendapatkan adanya hubungan bermakna antara menggunakan telepon genggam dengan nyeri kepala. ${ }^{3}$ Penelitian oleh Tandayu ${ }^{4}$ juga mengenai gambaran nyeri kepala primer pada mahasiswa kedokteran angkatan 2013 di Universitas Sam Ratulangi. ${ }^{4}$ Seiring dengan peningkatan pengguna ponsel pintar terjadi peningkatan kejadian nyeri kepala. Oleh karena itu, penulis tertarik untuk mulai melakukan penelitian lanjutan mengenai gambaran penggunaan ponsel pintar sebagai faktor risiko nyeri kepala primer pada mahasiswa angkatan 2013 Fakultas Kedokteran Universitas Sam Ratulangi.

\section{METODE PENELITIAN}

Jenis penelitian ini ialah deskriptif dengan desain potong lintang. Populasi penelitian ialah seluruh mahasiswa angkatan 2013 Fakultas Kedokteran Universitas Sam Ratulangi. Sampel penelitian ialah yang memenuhi kriteria inklusi sebagai berikut: mahasiswa yang bersedia ikut serta dalam penelitian dan kooperatif mengisi kuesioner. Kriteria eksklusi penelitian ini ialah mahasiswa yang mempunyai riwayat cedera kepala dan mahasiswa yang tidak hadir.

Variabel bebas yaitu intensitas penggunaan ponsel pintar, posisi saat menggunakan ponsel pintar, karakteristik sosiodemografik dalam hal ini jenis kelamin, sedangkan variabel tergantung yaitu nyeri kepala tipe tegang, migren tanpa aura, migren dengan aura, dan klaster. Data yang didapat melalui data primer menggunakan kuesioner dan disajikan dalam bentuk tabel dan diagram.

\section{HASIL PENELITIAN}

Berdasarkan penelitian yang dilakukan pada mahasiswa angkatan 2013 Fakultas Kedokteran Universitas Sam Ratulangi yang berjumlah 247 orang, didapatkan 243 mahasiswa yang memenuhi kriteria inklusi dan kesemuanya pernah mengalami nyeri kepala primer.

\section{Distribusi Frekuensi Berdasarkan Jenis Kelamin \\ Distribusi frekuensi berdasarkan jenis kelamin dari total 243 responden yaitu laki- laki sebanyak 72 responden (29.63\%) dan terbanyak yaitu perempuan dengan 171 responden $(70.37 \%)$.}

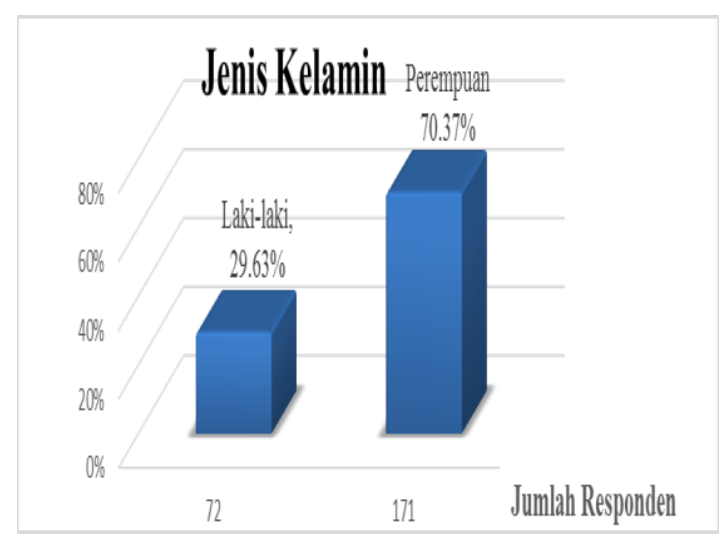

Gambar 1. Jenis Kelamin

\section{Distribusi Frekuensi Berdasarkan Jenis Nyeri Kepala Primer}

Distribusi frekuensi berdasarkan jenis nyeri kepala primer dari total 243 responden didapatkan nyeri kepala tipe tegang 177 responden $(72.84 \%)$, migren tanpa aura 42 responden (17.28\%), migren dengan aura 21 responden $(8.64 \%)$ dan nyeri kepala klaster 3 responden $(1.23 \%)$.

\section{Distribusi Frekuensi Berdasarkan Fitur yang Sering Digunakan}

Fitur yang sering di gunakan terbanyak adalah sosial media (Wa, line, ig, sc, path, dll). Responden yang menggunakan fitur sosial media yaitu sebanyak 204 responden $(40.16 \%)$. Sedangkan fitur lain yang 
digunakan adalah browsing (karya ilmiah, news, dll) sebanyak 124 responden $(24.41 \%)$, musik sebanyak 103 responden (20.28\%), dan game sebanyak 77 responden $(15.16 \%)$.

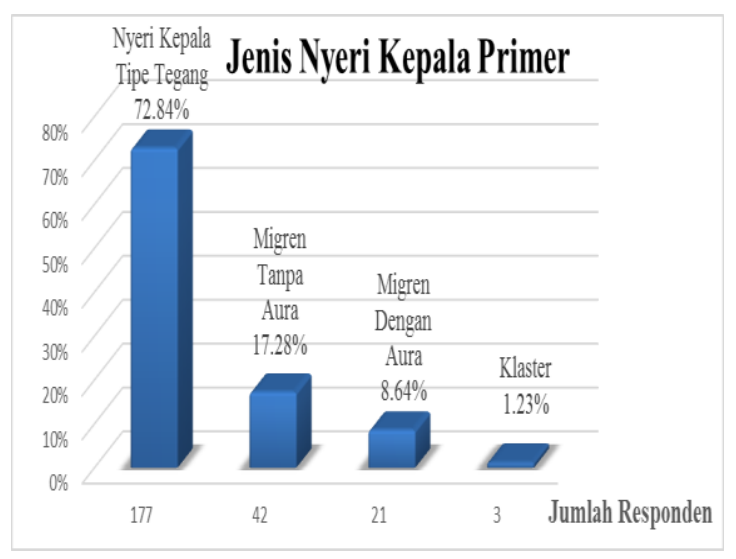

Gambar 2. Jenis Nyeri Kepala Primer

Distribusi Frekuensi Berdasarkan Lama Penggunaan Ponsel Pintar Dalam Sehari

Lama penggunaan ponsel pintar 5-7 jam dalam sehari menjadi yang tertinggi diantara yang lain dengan jumlah 115 responden (47.33\%). Sedangkan, lama penggunaan ponsel pintar $>7$ jam berjumlah 68 responden $(27.98 \%), 3-5$ jam berjumlah 50 responden $(20.58 \%),<3$ jam berjumlah 8 responden $(3.29 \%)$ dan yang tidak menjawab 2 responden $(0.82 \%)$.

\section{Distribusi Frekuensi Berdasarkan Keluhan Mata Saat Menggunakan Ponsel Pintar}

Responden yang menggunakan ponsel pintar, tercatat ada 157 responden $(64.61 \%)$ yang terdapat keluhan mata seperti mata kering, mata merah, dan penglihatan kabur saat menggunakan ponsel pintar, yang tidak terdapat keluhan mata ada 83 responden (34.16\%) dan yang tidak menjawab ada 3 responden $(1.23 \%)$.

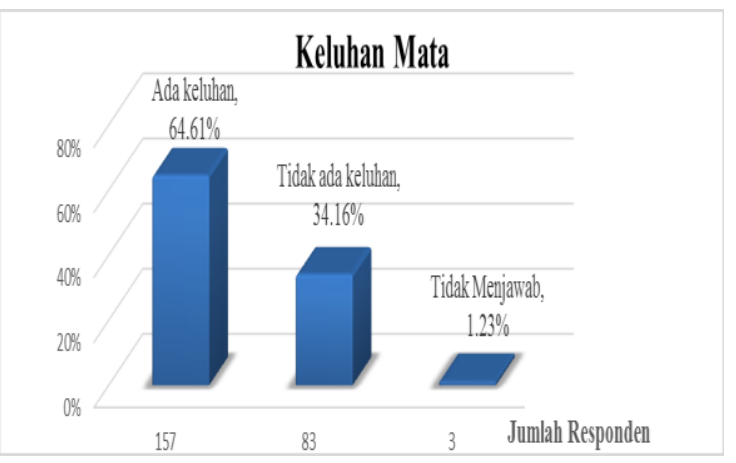

Gambar 3. Keluhan Mata

Tabel 1. Fitur yang Sering Digunakan

\begin{tabular}{cccc}
\hline No & Fitur Yang Sering Digunakan & Jumlah responden & \% \\
\hline \multirow{2}{*}{1} & Sosial Media (Whatsapp, Line, & 204 & $40.16 \%$ \\
& Instagram, SC, Path, dll) & & \\
2 & Browsing (karya Ilmiah, News, & 124 & $24.41 \%$ \\
3 & dll) & 103 & $20.28 \%$ \\
4 & Musik & 77 & $15.16 \%$ \\
& Game & $\mathbf{5 0 8}$ & $100.00 \%$ \\
\hline
\end{tabular}

Tabel 2. Lama Penggunaan Ponsel Pintar

\begin{tabular}{cccc}
\hline No & Lama Penggunaan Ponsel Pintar & Jumlah responden & \% \\
\hline 1 & > 7 jam & 68 & $27.98 \%$ \\
2 & 5-7 Jam & 115 & $47.33 \%$ \\
3 & 3-5 Jam & 50 & $20.58 \%$ \\
4 & < 3 Jam & 8 & $3.29 \%$ \\
5 & Tidak Menjawab & 2 & $0.82 \%$ \\
& Total & $\mathbf{2 4 3}$ & $100.00 \%$ \\
\hline
\end{tabular}


Distribusi Frekuensi Berdasarkan Aktivitas Fisik Dalam Seminggu

Aktivitas fisik $<2 x$ selama $>15$ menit dalam seminggu menjadi yang terbanyak yaitu 119 responden (48.88\%), diikuti dengan tidak pernah melakukan aktivitas fisik yaitu sebanyak 53 responden $(21.81 \%), 2-3 \mathrm{x}$ selama $>15$ menit 37 responden $(15.22 \%),>3 x$ selama $>15$ menit 18 responden $(7.40 \%)$, dan yang tidak menjawab sebanyak 16 responden (6.59\%).

\section{Distribusi Frekuensi Berdasarkan Posisi Saat Menggunakan Ponsel Pintar}

Posisi saat menggunakan ponsel pintar didominasi oleh responden yang menggunakan ponsel pintar dengan posisi kemiringan $30^{\circ}$ sebanyak 118 responden
$(48.56 \%)$ diikuti dengan kemiringan $45^{\circ}$ sebanyak 61 responden (25.10\%), kemiringan $15^{\circ}$ sebanyak 46 responden $(18.93 \%)$, kemiringan $60^{\circ}$ derajat sebanyak 11 responden $(4.56 \%)$, dan kemiringan $0^{\circ}$ sebanyak 7 responden $(2.88 \%)$.

\section{Distribusi Frekuensi Ponsel Pintar Sebagai Faktor Risiko Nyeri Kepala Primer \\ Data pada tabel di bawah, yang menggunakan ponsel pintar dan mengeluhkan nyeri kepala tipe tension type headache sebanyak 106 responden (75.71\%), migren tanpa aura sebanyak 23 responden (16.43\%), migren dengan aura 10 responden $(7.15 \%)$, klaster 1 responden $(0.71 \%)$.}

Tabel 3. Aktivitas Fisik

\begin{tabular}{cccc}
\hline No & Aktifitas Fisik & Jumlah responden & \% \\
\hline \hline 1 & > 3x selama > 15 menit & 18 & $7.40 \%$ \\
2 & 2-3x selama > 15 menit & 37 & $15.22 \%$ \\
3 & <x selama > 15 menit & 119 & $48.98 \%$ \\
4 & Tidak Pernah & 53 & $21.81 \%$ \\
5 & Tidak Menjawab & 16 & $6.59 \%$ \\
& Total & $\mathbf{2 4 3}$ & $100.00 \%$ \\
\hline
\end{tabular}

Tabel 4. Posisi Saat Menggunakan Ponsel Pintar

\begin{tabular}{cccc}
\hline No & $\begin{array}{c}\text { Posisi Saat Menggunakkan } \\
\text { Ponsel Pintar }\end{array}$ & Jumlah responden & \% \\
\hline \hline 1 & Kemiringan $60^{\circ}$ & 11 & $4.53 \%$ \\
2 & Kemiringan $45^{\circ}$ & 61 & $25.10 \%$ \\
3 & Kemiringan $30^{\circ}$ & 118 & $48.56 \%$ \\
4 & Kemiringan $15^{\circ}$ & 46 & $18.93 \%$ \\
5 & Kemiringan $0^{\circ}$ & 7 & $2.88 \%$ \\
& Total & $\mathbf{2 4 3}$ & $100.00 \%$ \\
\hline
\end{tabular}

Tabel 5. Ponsel Pintar Sebagai Faktor Risiko Nyeri Kepala Primer

\begin{tabular}{cccc}
\hline No & Jenis Nyeri Kepala Primer & $\begin{array}{c}\text { Ponsel } \\
\text { Pintar }\end{array}$ & $\%$ \\
\hline 1 & Tension Type Headache & 106 & $75.71 \%$ \\
2 & Migren Tanpa Aura & 23 & $16.43 \%$ \\
3 & Migren Dengan Aura & 10 & $7.15 \%$ \\
4 & Klaster & 1 & $0.71 \%$ \\
& Total & $\mathbf{1 4 0}$ & $100.00 \%$ \\
\hline
\end{tabular}




\section{BAHASAN}

Jenis nyeri kepala primer terbanyak yang diketahui berdasarkan penelitian ini yaitu nyeri kepala tipe tegang $72.84 \%$. Berdasarkan hasil penelitian multisenter berbasis rumah sakit pada 5 rumah sakit di Indonesia, didapatkan nyeri kepala tipe tegang menempati posisi pertama. Dengan episodic tension type headache (ETTH) $31 \%$, chronic tension type headache $(\mathrm{CTTH}) 24 \%$, migren tanpa aura $10 \%$, migren dengan aura $1.8 \%$, nyeri kepala klaster $0.5 \% .^{2}$

Fitur yang sering digunakan terbanyak adalah sosial media (Wa, line, ig, sc, path, dll) yaitu $40.16 \%$. Data tersebut sesuai dengan penelitian dari yahoo TNS mobile index Indonesia 2013 yaitu media sosial menempati tempat terbanyak, diikuti dengan akses email kemudian pencarian informasi (browsing). ${ }^{5}$ Ponsel pintar melayani kita dengan fitur-fitur menarik dan tak menarik sekalipun. Karena ponsel pintar sudah menjadi bagian dari gaya hidup akhirnya para pengguna hanya memakai itu dikarenakan eksistensi. Hal tersebut memberikan dampak negatif terhadap penggunaan ponsel pintar yang tidak benar. ${ }^{6}$ Salah satu dampak negatif seusai dengan penelitian ini yaitu fitur yang sering digunakan dalam hal ini browsing mengenai karya ilmiah dan news yang dapat memberikan informasi bermakna bagi pembacanya menempati posisi kedua.

Penggunaan ponsel pintar 5-7 jam dalam sehari menjadi yang tertinggi diantara yang lain yaitu $47.33 \%$. Penggunaan ponsel pintar di Indonesia menurut survey Brown diawal tahun 2014 adalah 181 menit per hari. Hal ini menjadikan Indonesia berada di posisi pertama untuk penggunaan ponsel pintar terlama di Dunia. ${ }^{7}$ Dengan layanan internet 24 jam, ponsel pintar akan bergetar atau berdering setiap saat, karena itu setiap saat pula penggunanya akan memainkan ponsel pintarnya. Hal inilah yang menyebabkan para pengguna ponsel pintar banyak menghabiskan waktu untuk memainkan ponsel pintarnya. ${ }^{6}$

Tercatat $64.61 \%$ terdapat keluhan mata seperti mata kering, mata merah, dan penglihatan kabur saat menggunakan ponsel pintar. Penelitian pada siswa kelas 11 jurusan UPW di SMKN 1 Gorontalo, terdapat keluhan mata yaitu $91.9 \% .{ }^{8}$ Untuk keluhan pada mata yaitu mata merah bisa disebabkan karena injeksi sinar yang mempunyai riwayat kemungkinan penyebabnya adalah rasa tidak tahan pada cahaya, mata kering dapat terjadi akibat kurangnya produksi air mata, penglihatan menjadi kabur karena otot-otot okular mata yang terlalu tegang yang bisa mengakibatkan seseorang untuk tidak bisa fokus atau penglihatan menjadi kabur. Nyeri kepala sering dihubungkan dengan mata. Keluhan nyeri kepala dapat disebabkan oleh: kelainan mata, kelelahan mata, ketegangan mata yang diakibatkan penggunaan mata yang berlebihan. ${ }^{9,10}$ Perbedaan hasil di atas mungkin dikarenakan adanya perbedaan jarak antara mata dengan layar ponsel pintar, pencahayaan ruangan, dan lamanya jeda istirahat saat menggunakan ponsel pintar.

Aktivitas fisik $<2 \mathrm{x}$ selama $>15$ menit dalam seminggu adalah yang terbanyak yaitu $48.98 \%$, diikuti dengan yang tidak pernah melakukan aktivitas fisik yaitu $21.81 \%$. Penelitian yang dilakukan oleh Veugelers, 2013 di Kanada 64\% terjadi penurunan aktivitas fisik yang bekaitan dengan penggunaan electronic entertainment and communication devices (EECDs). ${ }^{12}$ Perkembangan teknologi membuat penggunanya duduk terlalu lama dengan menatap layar ponsel pintarnya sehingga menjadikan tubuh tidak bergerak.

Posisi saat menggunakan ponsel pintar, dari penelitian kali ini umumnya didominasi oleh responden yang menggunakan ponsel pintar dengan posisi kemiringan $30^{\circ}$ yaitu $48.56 \%$. Posisi yang tidak benar khususnya fleksi leher dan sikap tubuh yang statis berhubungan dengan nyeri leher dan nyeri kepala dimana otot-otot leher berperan penting pada patogenesis migrain juga memfasilitasi sensitisasi sentral. ${ }^{13}$ Posisi kepala yang menetap mengakibatkan kontraksi otot-otot kepala dan leher dalam jangka waktu lama 
Oroh, Pertiwi, Runtuwene: Gambaran penggunaan ponsel...

juga dapat menyebabkan nyeri kepala tipe tegang. ${ }^{14}$

Pengguna ponsel pintar yang mengeluhkan nyeri kepala tipe tegang yaitu $75.71 \%$, migren tanpa aura $16.43 \%$, migren dengan aura 10 responden $7.15 \%$, klaster 1 responden $0.71 \%$. Satu hipotesis tentang bagaimana nyeri kepala dapat berhubungan dengan penggunaan ponsel pintar adalah bahwa tampilan ponsel pintar yang di tempatkan terlalu rendah dapat meningkatkan beban pada otot leher, dan penggunaan ponsel pintar $>56 \mathrm{jam} / \mathrm{minggu}$ rasio prevalensi secara signifikan meningkat untuk nyeri leher atau nyeri bahu, dan kelelahan mata yang berhubungan dengan nyeri kepala. ${ }^{15}$ Berbagai fitur yang disediakan oleh ponsel pintar membuat para penggunanya banyak menghabiskan waktu untuk berinteraksi dengan layar ponsel. Menggunakan ponsel pintar terlalu lama menyebabkan berbagai dampak negatif bagi para penggunanya seperti membuat ketagihan yang berdampak pada aktivitas fisik yang kurang, mengganggu tidur, dan membahayakan mata. ${ }^{6}$

\section{SIMPULAN DAN SARAN}

Dari penelitian ini ditemukan bahwa penggunaan ponsel pintar yang terlalu lama karena berbagai fitur yang disediakan menyebabkan kurangnya aktivitas fisik dan adanya keluhan pada mata serta posisi yang salah saat menggunakan ponsel pintar merupakan faktor risiko terjadinya nyeri kepala primer. Jenis nyeri kepala terbanyak ialah tipe tegang sedangkan yang paling sedikit ialah nyeri kepala klaster.

\section{DAFTAR PUSTAKA}

1. WHO. Headache disorders. 201212 [diakses 4 Sep 2016]. Tersedia di:http://www.who.int/mediacentre/fa ctsheets/fs277/en

2. Sjahrir H. Nyeri Kepala. Edisi ke-11. Medan: USU press; 2004.

3. Nurwulandari. Hubungan penggunaan media elektronik dengan nyeri kepala pada remaja di Surakarta [skripsi].
[Surakarta]:

Universitas

Muhammadiyah; 2014.

4. Tandaju Y. Gambaran nyeri kepala primer pada mahasiswa angkatan 2013 fakultas kedokteran Universitas Sam Ratulangi Manado [skripsi]. [Manado]. Universitas Sam Ratulangi; 2016.

5. Yahoo TNS mobile index Indonesia. Indonesia highlights. April 2013 [diakses 21 November 2016]. Tersedia di:http://ddw.in/insea/insights/YahooNetIndex-ID-2013.pdf

6. Noava M. Pengaruh peggunaan smartphone terhadap nilai akademik mahasiswa. 2013;4:5-7.

7. Brown M. AdReaction. Marketing in a multiscreen world. 2014:10.

8. Sanu KM. Hubungan intensitas penggunaan smartphone dengan adanya keluhan penglihatan pada siswa kelas xi jurusan UPW di SMKN 1 Kota Gorontalo [skripsi]. [Gorontalo]. Universitas Negeri Gorontalo; 2015.

9. Ilyas, Sidrata. Penuntun ilmu penyakit mata. Jakarta: FKUI; 2003.

10. Rangkuti IY. Perilaku remaja mengenai penggunaan gadget terhadap keluhan kelelahan mata di SMAN 6 Medan tahun 2015 [skrisi]. [Medan]: Universitas Sumatera Utara; 2015.

11. Chahal H, Fung C, Kuhle S, Veugelers PJ. Availability and night-time use of electronic entertainment and communication devices are associated with short sleep duration and obesity among Canadian children. Pediatr obes. 2013;8:42-51.

12. Shevel E, Spiering EH. Cervical muscles in the pathogenesis of migrain headache. Headache pain. 2004;5:12-4.

13. Akbar M. Nyeri kepala. Talk show "dokter anda menyapa" yang diselenggarakan oleh TVRI Sulawesi Selatan; 24 Jan 2010; Makassar: 2010.

14. Palm P, Risberg EH, Mortimer M, Palmerud G, Toomingas A, Tornqvist EW. Computer use, neck and upper extremity symptoms, eyestrain and headache among female and male upper secondary school student. SJWEH Suppl. 2007;3:33-41. 